University of Nebraska - Lincoln

DigitalCommons@University of Nebraska - Lincoln

Faculty Publications, Department of Psychology

Psychology, Department of

March 2001

\title{
Individual differences in rat locomotor activity are diminished by nicotine through stimulation of central nicotinic acetylcholine receptors
}

Rick A. Bevins

University of Nebraska-Lincoln, rbevins1@unl.edu

Joyce Besheer

University of Nebraska-Lincoln

Follow this and additional works at: https://digitalcommons.unl.edu/psychfacpub

Part of the Psychiatry and Psychology Commons

Bevins, Rick A. and Besheer, Joyce, "Individual differences in rat locomotor activity are diminished by nicotine through stimulation of central nicotinic acetylcholine receptors" (2001). Faculty Publications, Department of Psychology. 197.

https://digitalcommons.unl.edu/psychfacpub/197

This Article is brought to you for free and open access by the Psychology, Department of at DigitalCommons@University of Nebraska - Lincoln. It has been accepted for inclusion in Faculty Publications, Department of Psychology by an authorized administrator of DigitalCommons@University of Nebraska - Lincoln. 


\title{
Individual differences in rat locomotor activity are diminished by nicotine through stimulation of central nicotinic acetylcholine receptors
}

\author{
Rick A. Bevins and Joyce Besheer \\ Department of Psychology, University of Nebraska-Lincoln \\ Submitted July 2000; revised September 2000; accepted September 2000.
}

\begin{abstract}
An increasing body of research has focused on isolating factors that predict or alter individual differences in the behavioral and neural processes mediating the effects of abused drugs. Within this framework, the current report assessed individual differences and the locomotor effect of nicotine. Rats were screened for activity induced by a novel environment. Rats, which were more active to initial environment exposure, remained more active even after seven additional 30-min exposures to the same environment. Treatment with nicotine-di-D tartrate $(1 \mathrm{mg} / \mathrm{kg}, \mathrm{sc})$ disrupted this effect. This nicotine disruption of individual differences occurred whether nicotine suppressed locomotor activity (initial administration) or stimulated locomotor activity (seventh and eighth administration). Mecamylamine (1 $\mathrm{mg} / \mathrm{kg}$ ), but not hexamethonium $(10 \mathrm{mg} / \mathrm{kg}$ ), completely blocked the suppressant and stimulant effects of nicotine. Further, mecamylamine restored the nicotine-induced disruption of individual differences; hexamethonium had no effect. This data pattern suggests that the disruptive effects of acute and chronic nicotine on individual differences were mediated by neural nicotinic acetylcholine (nACh) receptors.
\end{abstract}

Keywords: Dopamine, Hexamethonium, Locomotor sensitization, Nicotinic acetylcholine, Novelty, Stress

Rats exposed to a small inescapable environment are more active when the environment is novel than when it is familiar (Refs. [23,33]; see later). Recently, the empirical and theoretical interest in the behavioral activating effect of novelty has increased. This interest is driven, in part, by evidence indicating that reactivity to a novel environment is a behavioral measure of a rat's sensitivity to stress. Rats exposed to a novel environment show an increase in plasma levels of the "stress hormone" corticosterone (e.g., Ref. [25]). Importantly, novelty-induced increases in corticosterone are greater in rats that display more locomotor activity to an inescapable novel environment [29]. Moreover, rats more activated by exposure to a novel environment [often termed high responders (FIR)] displayed a greater increase in corticosterone levels to restraint stress than rats that were less reactive to the novel environment [low responders (LR)]. HR also had a more prolonged increase in corticosterone to this restraint than LR [10]. This work is important because it demonstrates that a purported behavioral measure of stress sensitivity (i.e., novelty-induced activity) predicts the response to another form of stress (i.e., restraint).
Reactivity to a novel environment has served as a predictive variable in recent drug abuse studies (see Refs. [9,31 ] for reviews). This predictive value is another reason for the recent interest in novelty-induced activity. For instance, rats that are more activated by exposure to a novel environment (HR) more readily self-administer amphetamine and are more sensitive to the locomotor-stimulant effects of amphetamine [29]. Novelty-induced activity has been found to also predict such behavioral effects as activity induced by cocaine and caffeine [16], ethanol-induced activity and ethanol self-administration [14,15], amphetamine-conditioned hyperactivity to contextual stimuli [17], cueing effects of amphetamine [13] and amphetamine barpress suppressant effects [6].

Another factor contributing to the interest in novelty-induced activity is the potential insight it may provide into the behavioral and neural substrates underlying individual differences in drug abuse vulnerability. This idea is based, in part, on the assumption that the predictive relation just described likely reflects an overlap in the mechanism(s) responsible 
for an individual's sensitivity to novelty and abused drugs [9,29,31]. Indeed, there is strong empirical evidence to support this assumption. For instance, acute and chronic locomotor effects of amphetamine in rats are enhanced when drug administration occurs in a novel rather than a familiar environment $[3,4]$. Similar enhancement of drug responses occurs when rats are exposed to stressors other than a novel environment (e.g., Refs. [1,24,30]).

Much of the individual-differences research in rats has used amphetamine as the prototypical psychomotor stimulant. Individual differences and the psychomotor effects of nicotine have received much less empirical attention (see Refs. $[28,35])$. Thus, one major goal of the present report was to elucidate the relation between novelty-induced activity and the subsequent acute and chronic locomotor effects of ( -)nicotine-di-D tartrate. Acute nicotine can produce a biphasic effect on locomotor activity. Depending on such factors as dose and apparatus, nicotine initially suppresses locomotor activity in rats $[7,36,37]$. Chronically, nicotine tends to stimulate activity $[7,19,20]$. There have been past reports of a predictable relation between a rat's nondrugged activity level in a novel environment and its later sensitivity to the locomotor effects of nicotine. Rats classified as HR appeared more sensitive to the locomotor-depressant effects of nicotine; LR appeared more sensitive to the stimulant effects of nicotine (e.g., Ref. [34]). Although this outcome is empirically interesting, it is susceptible to a baseline-dependency interpretation [11,28]. That is, HR may have shown greater sensitivity to the locomotor-suppressant effects of nicotine simply because their baseline activity was higher in the novel environment. Similarly, LR likely showed a larger relative increase in activity because their activity was initially lower.

In the present report, we sought to examine whether reactivity to novelty was related to the later sensitivity of acute and chronic nicotine using an experimental protocol more comparable to recent individual differences research with other drugs of abuse (cf. Refs. [6,16,29]; see Section 1.4). To do so, we had rats that were repeatedly treated with ( - )-nicotinedi-D tartrate and an injection-matched saline control. Further, we assessed individual differences in a manner that was much less susceptible to a baseline-dependency interpretation (i.e., z-score transformation; see later). A second major goal of the present study was to determine whether the central and peripheral nicotinic acetylcholine (nACh) receptor antagonist mecamylamine or the peripheral $\mathrm{nACh}$ receptor antagonist hexamethonium affected individual differences in nicotine-treated rats. That is, does novelty-induced activity predict sensitivity to antagonism of the acute and/or chronic effects of nicotine? No one has assessed individual differences in the sensitivity to $\mathrm{nACh}$ receptor antagonism of the effect of nicotine. Indeed, there are relatively little individual differences research on the sensitivity to receptor antagonism whether the animal has or has not been treated with a drug of abuse [8]. This technique is an overlooked tool for identifying the processes mediating individual differences.

\section{Methods}

\subsection{Animals}

The animals were 134 male Sprague-Dawley rats (mean body weight $=355 \mathrm{~g}$ ) obtained from Harlan Industries (Indianapolis, IN). They were housed individually in a colony that was on a 12-h light/dark cycle. Experiments were conducted during the light phase of this cycle. The rats had free access to food and water while in the home cage. Each rat was handled for $1 \mathrm{~min}$ on at least 2 days prior to the start of an experiment. We minimized handling experience given the evidence indicating that too much exposure to the experimental protocol could alter individual differences; this alteration is likely due to shifts in sensitivity to mild stressors like exposure to a novel environment (cf. Ref. [9]).

\subsection{Drugs}

( -)-Nicotine-di-D tartrate, mecamylamine hydrochloride (Research Biochemicals International, Natick, MA), and hexamethonium bromide (Sigma, St. Louis, MO) were mixed in saline $(0.9 \% \mathrm{NaCl})$. The $\mathrm{pH}$ of nicotine was brought to 7.0 \pm 0.1 with a dilute sodium hydroxide solution. Dosages were based on the salt form of the drug and injections were subcutaneous at a volume of $1 \mathrm{ml} / \mathrm{kg}$.

\subsection{Apparatus}

Activity was automatically recorded in one of eight circular chambers made from white PVC pipe. The inside diameter of each chamber was $30.5 \mathrm{~cm}$ and the top edge of the chamber was $45 \mathrm{~cm}$ from the wire mesh floor. Each chamber was equipped with two infrared emitter/detector units. The infrared units were mounted $4 \mathrm{~cm}$ above the mesh floor such that the chamber was divided into four equal sections. Each time the rat broke the infrared beam, a count was automatically sent to an interface and then recorded by a personal computer. Activity was defined as the number of infrared beam breaks in predetermined time intervals. The chambers were located in a room adjacent to the animal colony. Fluorescent ceiling lights provided general illumination and a continuous white noise served to mask external sounds.

\subsection{Procedure}

\subsubsection{Mecamylamine}

Rats were assigned to one of four conditions (16 rats per condition) before baseline activity in the novel chambers was assessed. Novelty-induced activity for 36 rats was obtained on Day I. Each rat was injected subcutaneously with saline and then placed in a circular chamber where activity was monitored for $1 \mathrm{~h}$. The remaining 28 rats were screened for baseline activity on Day 2. All rats stayed in their home cages on Day 3. Starting on Day 4, each rat received two injections before placement in the chamber. Two 
sets of rats received a subcutaneous injection of mecamylamine ( 0.1 or $1.0 \mathrm{fig} / \mathrm{kg}$ ) $15 \mathrm{~min}$ before an injection of $1 \mathrm{mg} / \mathrm{kg}(-)$-nicotine-di-D tartrate $(0.351 \mathrm{mg} / \mathrm{kg}$ free base). Immediately after the nicotine injection, rats were placed in the locomotor chambers where activity was monitored for $30 \mathrm{~min}$. A third set was treated similarly except the mecamylamine injection was replaced by a saline injection. The last set of rats received saline for both injections. This latter set provided a no-drug baseline for comparison. The procedures of Day 4 were repeated once daily for seven trials. On Day 11, all rats received a subcutaneous injection of ()-nicotine-di-D tartrate $(1 \mathrm{mg} / \mathrm{kg})$ immediately before placement in the chamber; the pretreatment injection was precluded on this nicotine-alone test day.

\subsubsection{Hexamethonium}

Mecamylamine blocks central and peripheral nACh receptors [21]. To determine the contribution of peripheral vs. central $\mathrm{nACh}$ receptors to any individual differences effect, we conducted an additional experiment in which rats were pretreated with the peripheral $\mathrm{nACh}$ antagonist hexamethonium [2]. The four conditions (18 rats per condition except the saline-treated control had 16 rats) and the procedural details were similar to the mecamylamine experiment except that hexamethonium (5 or $10 \mathrm{fig} / \mathrm{kg}$ ) replaced mecamylamine and was injected subcutaneously $20 \mathrm{~min}$ before the (-)-nicotinedi-D tartrate injection (cf. Ref. [7]). Also, the day intervening between the screen for novelty baseline and the first day of nicotine treatment (i.e., Day 3) was eliminated. Rats had served in an unrelated experiment; they were drug naive and had never experienced the circular locomotor chambers.

\subsection{Data analysis}

\subsubsection{Overall activity}

To allow comparison with the published literature in this area, we report overall activity counts (i.e., beam breaks) for each experiment. Initial omnibus analyses were analysis of variance (ANOVA); two-way repeated measure for Trials 1-7 data and a one-way ANOVA for the nicotine-alone test. Post hoc tests, prompted by a significant effect, were used to determine the source of the differences. Statistical significance was set at a two-tailed alpha of .05. If a post hoc contrast was not described, then the comparison was not statistically significant.

\subsubsection{Individual differences}

The main goal of the present report was to determine whether novelty-induced activity predicted subsequent effects of nicotine and whether the antagonist mecamylamine or hexamethonium altered these effects in a systematic manner. For each condition, we converted the total number of beam breaks during the $1-\mathrm{h}$ exposure to the novel chamber to a $z$-score. We then divided rats in each condition into two groups. Rats with positive $z$-scores (upper portion of the ac- tivity distribution) were designated as HR; rats with negative $z$-scores were designated LR. We then examined whether HR and LR differed on Trial 1, Trial 7, or the nicotine-alone test. Importantly, activity on these days was also converted to zscores before comparing HR and LR statistically with pairwise $t$ tests. By normalizing the activity data with a $z$-score conversion before analyses, we could determine whether HR and LR on novelty-induced activity changed their relative position in the distribution across experimental treatment. That is, regardless of whether locomotor activity was suppressed or inflated relative to inescapable novelty, all the distributions had a mean of 0 and a standard deviation of 1 . Thus, would rats in the positive portion of the z-distribution during the inescapable novelty screen (i.e., HR) remain in the upper portion across repeated nicotine treatment? If so, this result would indicate that reactivity to novelty predicts nicotine-induced activity.

\section{Results}

\subsection{Overall activity}

\subsubsection{Mecamylamine}

Activity in the inescapable novel environment did not differ across the four drug conditions, $F<1$ (data not shown). Fig. 1A shows the activity counts (number of infrared beam breaks) across the first seven trials. On Trial 5, there was a misalignment of an emitter/detector unit. Rather than using estimation procedures to fill in the missing counts for these rats, we dropped this trial from the analyses and figure. There was a significant effect of drug condition $(F(3$, $60)=3.23, P<.05]$, of trial $(F(5,300)=22.05, P<.001]$ and a significant Condition $\times$ Trial interaction $(F(15,300)$ $=15.27, P<.001]$. Post hoc LSD tests revealed that relative to the no-drug control $(0 \mathrm{Mec} / 0 \mathrm{Nic})$, rats treated with only nicotine $(0 \mathrm{Mec} / 1 \mathrm{Nic})$ showed a significant decrease in activity on the first trial. Mecamylamine completely blocked this acute suppressive effect of nicotine. In fact, rats treated with the high dose of mecamylamine $(1 \mathrm{Mec} / 1 \mathrm{Nic})$ increased activity above the no-drug control on Trial $1 \mathrm{Mec} / 1 \mathrm{Nic}$ was statistically similar to the control. In contrast, the nicotinealone group $(0 \mathrm{Mec} / 1 \mathrm{Nic})$ and the group pretreated with the low dose of mecamylamine $(0.1 \mathrm{Mec} / 1 \mathrm{Nic})$ displayed an increase in activity across trials. Group $0 \mathrm{Mec} / 1 \mathrm{Nic}$ was significantly more active than the control group on Trials 3-7. Group $0.1 \mathrm{Mec} / 1 \mathrm{Nic}$ was more active than controls on Trials 2-7; this group also differed significantly from Group 0Mec/ $1 \mathrm{Nic}$ on Trial 2. Finally, Groups $0 \mathrm{Mec} / 1 \mathrm{Nic}$ and $0.1 \mathrm{Mec} /$ $1 \mathrm{Nic}$ were significantly more active than Group $1 \mathrm{Mec} / 1 \mathrm{Nic}$ on the last two trials. In short, pretreatment with mecamylamine blocked nicotine-induced locomotor suppression $(0.1$ and $1 \mathrm{mg} / \mathrm{kg}$ mecamylamine); the high dose of mecamylamine $(1 \mathrm{mg} / \mathrm{kg})$ also blocked the subsequent locomotor-activating effects of nicotine. 


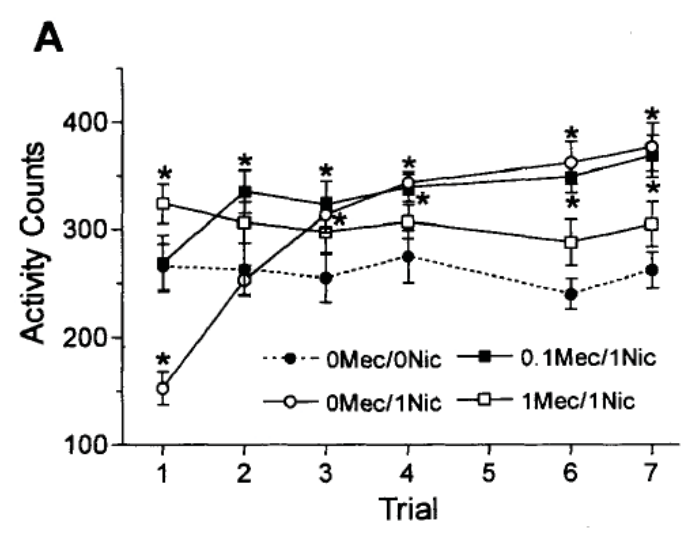

B

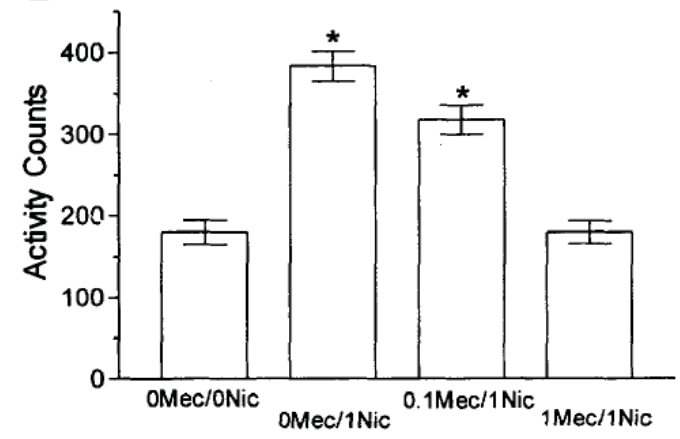

Fig. 1. Panel A shows the mean level of activity ( \pm 1 S.E.M.) across the seven trials for each drug condition in the mecamylamine experiment. The number before the letter in group names denotes the dose of drug in milligrams per kilogram $[\mathrm{Mec}=$ mecamylamine and $\mathrm{Nic}=(-)$-nicotine-di-D tartrate $]$. Panel B shows the mean activity level during the nicotine-alone test for each drug condition in the mecamylamine experiment. Asterisks denote a significant difference $(P<.05)$ from the no-drug control $(0 \mathrm{Mec} / 0 \mathrm{Nic})$.

Fig. 1B shows the overall activity counts in the nicotine-alone test for each group (i.e., Day 11 ). Recall that all rats received an injection of ( -)-nicotine-di-D tartrate $(1 \mathrm{mg} / \mathrm{kg})$ immediately before placement in the locomotor chambers; mecamylamine injections were withheld on this day. The ANOVA revealed a significant effect of drug condition $[F(3,60)=40.31, P$ $<.001]$. Post hoc tests comparing each group with the no-drug control (0Mec/0Nic) found that Group 0Mec/1Nic was significantly more active. This result is not surprising considering that this test reflects the first nicotine injection for the control group (i.e., acute locomotor suppression by nicotine). Rats previously treated with the low dose of mecamylamine $(0.1 \mathrm{Mec} / 1 \mathrm{Nic})$ were also more active than the no-drug control group. However, rats 7 previously treated with the high dose of mecamylamine $(1 \mathrm{Mec} / 1 \mathrm{Nic})$ did not differ from controls $(0 \mathrm{Mec} / 0 \mathrm{Nic})$. Thus, in a nicotine-alone test, previous pretreatment with the high dose of the nACh receptor antagonist mecamylamine completely blocked tolerance to the suppressant effects of nicotine. That is, even though rats in Group 1Mec/1Nic had seven previous injections of nicotine, their locomotor behavior was comparable to rats that had never received nicotine before this test.

\subsubsection{Hexamethonium}

Novelty-induced activity did not differ statistically across the four conditions, $F<1$ (data not shown). Fig. 2A shows the activity counts for each condition across the first seven trials. There was a significant effect of trial $[F(6,396)=$ $50.20, P<.001]$, and a significant Condition $\times$ Trial interaction $[F(18,396)=18.41, P<.001]$. The main effect of dose was not significant $[F(3,66)=1.00, P=.399]$. LSD tests revealed that activity was suppressed by nicotine on the first trial regardless of the hexamethonium dose. However, the high dose of hexamethonium $(10 \mathrm{Hex} / 1 \mathrm{Nic})$ partially blocked this suppressant effect. Group $10 \mathrm{Hex} / 1 \mathrm{Nic}$ was more active than the other two groups treated with nicotine. On Trial 2, significant suppression relative to the no-drug control was seen in rats receiving nicotine alone $(0 \mathrm{Hex} / 1 \mathrm{Nic})$ or the low dose of hexamethonium $(5 \mathrm{Hex} / 1 \mathrm{Nic})$ but not in the rats pretreated with $10 \mathrm{mg} / \mathrm{kg}$ hexamethonium. Group $10 \mathrm{Hex} / 1 \mathrm{Nic}$ was more active than the nicotine-alone group on Trial 2. Finally, all groups were significantly more active than the nodrug control on Trials 4-7.
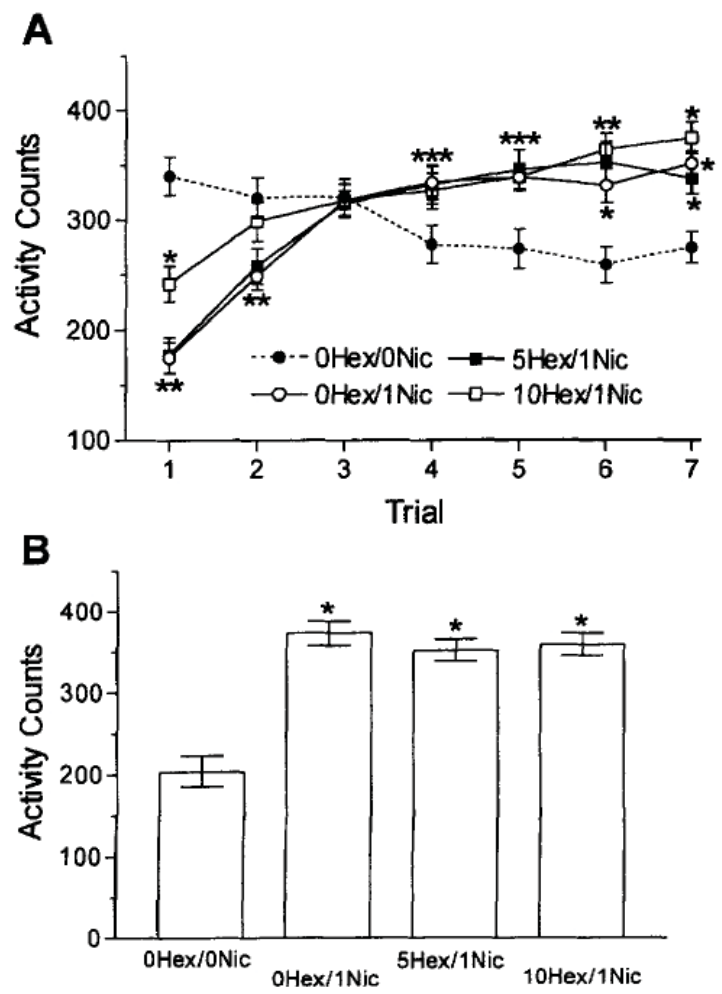

Fig. 2. Panel A shows the mean level of activity ( \pm 1 S.E.M.) across the seven trials for each drug condition in the hexamethonium experiment. The number before the letter in group names denotes the dose of drug in milligrams per kilogram $[\mathrm{Hex}=$ hexamethonium and $\mathrm{Nic}=(-)$-nicotine-di-D tartrate]. Panel B shows the mean activity level during the nicotine-alone test for each drug condition in the hexamethonium experiment. Asterisks denote a significant difference $(P<. \mathrm{O} 5)$ from the no-drug control $(0 \mathrm{Hex} / 0 \mathrm{Nic})$. 

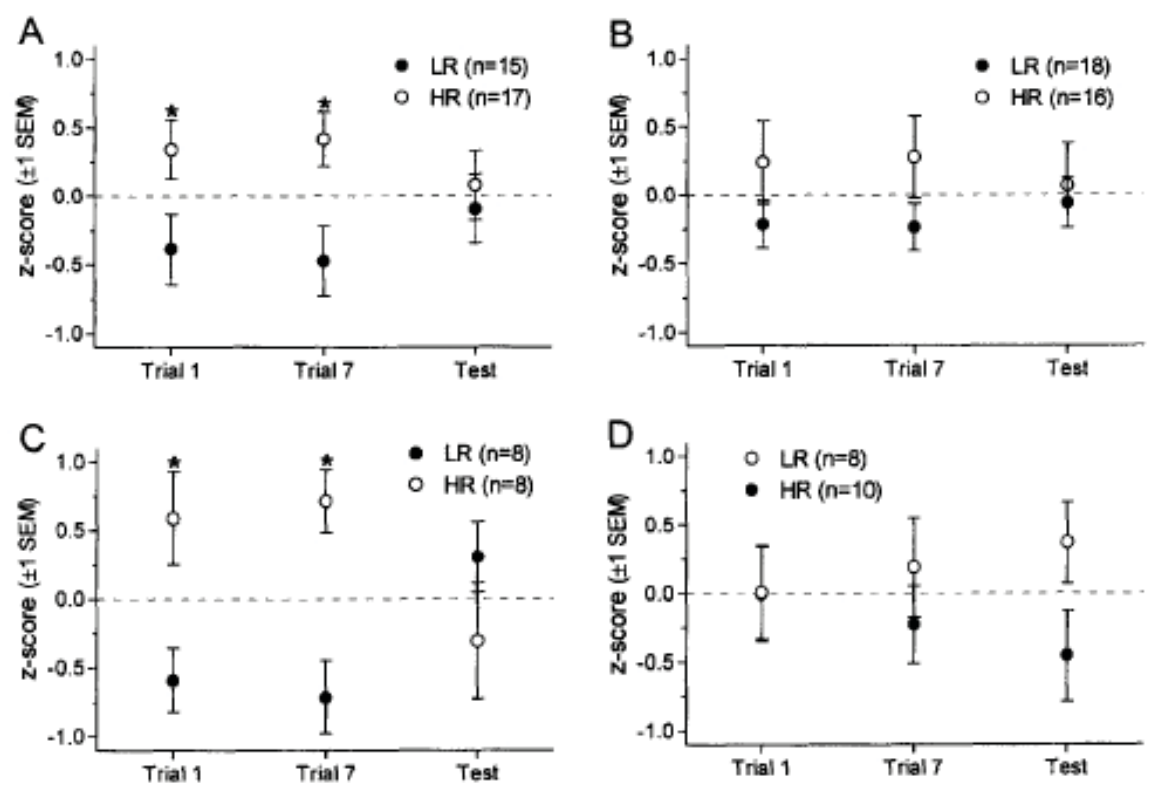

Fig. 3. Panel A shows the mean z-score ( \pm 1 S.E.M.) on Trial 1, Trial 7, and the nicotine-alone test for saline control rats classified as HR and LR based on activity induced by a novel environment. Rats in the saline controls from the mecamylamine $(0 \mathrm{Mec} / 0 \mathrm{Nic})$ and the hexamethonium $(0 \mathrm{Hex} / 0 \mathrm{Nic})$ experiments were pooled into one large group. Panel B displays the mean $z$-score on Trial 1, Trial 7, and the nicotine-alone test for HR and LR in the groups treated with only nicotine (Groups $0 \mathrm{Mec} / 1 \mathrm{Nic}$ and $0 \mathrm{Hex} / 1 \mathrm{Nic}$ ). Panel C shows the mean $z$-scores for HR and LR pretreated with the $1-\mathrm{mg} / \mathrm{kg}$ dose of mecamylamine before each of the seven trials of nicotine administration (Group 1Mec/1Nic). Panel D shows the mean $z$-scores for HR and LR pretreated with the 10-mg/kg dose of hexamethonium before each of the seven trials of nicotine administration (Group 10Hex/1Nic). Asterisks denote a significant difference $(P<.05)$ from the comparable LR group.

Fig. 2B shows the activity counts for each group in the nicotine-alone test. That is, hexamethonium was withheld and all rats received a $1-\mathrm{mg} / \mathrm{kg}$ injection of ( -)-nicotine-di-D tartrate immediately before locomotor testing. Cotreatment of hexamethonium and nicotine did not appear to alter the subsequent psychomotor effects of nicotine alone. The ANOVA revealed a significant effect of group $[F(3,66)=26.09, P<.001]$. Contrasts revealed that all groups previously treated with nicotine were more active than the no-drug control $(0 \mathrm{Hex} / 0 \mathrm{Nic})$ which was treated with nicotine for the first time on this day.

\subsubsection{Individual differences}

The mecamylamine and the hexamethonium experiments included a set of rats that received only saline for the 7 days following exposure to an inescapable novel environment (Groups $0 \mathrm{Mec} / 0 \mathrm{Nic}$ and $0 \mathrm{Hex} / 0 \mathrm{Nic}$ ). To increase the power of our individual differences analyses, we pooled the two sets into one large group $(n=32)$ before converting the activity data for inescapable novelty, Trial 1 , Trial 7 , and the nicotine-alone test to $z$-scores and splitting the rats into HR and LR based on performance during inescapable novelty (see Fig. 3A). On Trials 1 and 7, HR had significantly higher $z$ scores than LR $[t(30) \geq 2.17, P \leq .038]$. This data pattern indicates that saline control rats retained their relative position in the distribution even though overall activity was decreasing across trials (i.e., environmental familiarization). Interestingly, initial exposure to nicotine on the test day disrupted this difference, $t<1$. Analysis of the pooled data for rats that received only nicotine (Groups $0 \mathrm{Mec} / 1 \mathrm{Nic}$ and $0 \mathrm{Hex} / 1 \mathrm{Nic} ; n=$
34) confirmed this effect of nicotine administration (see Fig. $38)$. HR did not differ statistically from LR on any day [t(32) $\leq 1.52, P \geq .139$, indicating that nicotine, whether a locomotor suppressant (Trial 1) or a stimulant (Trial 7 and test), disrupted individual differences.

Fig. 3C shows the individual differences data for rats pretreated with the $1-\mathrm{mg} / \mathrm{kg}$ dose of mecamylamine before each of the seven trials of nicotine administration (Group 1Mec/ $1 \mathrm{Nic})$. Mecamylamine restored the individual differences that were disrupted by nicotine alone (Groups $0 \mathrm{Mec} / 1 \mathrm{Nic}$ and $0 \mathrm{Hex} / 1 \mathrm{Nic})$. HR were significantly greater than LR on Trials 1 and $7[t(14) \geq 2.88, P \leq .012]$, indicating rats classified in the upper portion of the activity distribution during inescapable novelty remained there when mecamylamine was administered before nicotine. Again, nicotine alone on the test day disrupted the difference between HR and LR $[t(14)=1.25, P$ $=.233]$. Unlike mecamylamine, hexamethonium $(10 \mathrm{mg} / \mathrm{kg})$ did not reinstate individual differences disrupted by nicotine (see Fig. 3D). HR and LR were statistically similar on Trial 1 , Trial 7, and on the nicotine-alone test day $[t(16) \leq 1.85, P \geq$ .083]. The data from the intermediate doses of mecamylamine $(0.1 \mathrm{mg} / \mathrm{kg})$ and hexamethonium $(5 \mathrm{mg} / \mathrm{kg})$ are not shown because they are similar to the nicotine-alone condition and thus, do not add to the conclusions.

\section{Discussion}

Previous research has shown that acute treatment with nicotine can suppress locomotor activity in rats [7,36,37]. 
Depending on the conditions of the experiment, this suppression can be quickly replaced by locomotor-activating effects $[7,19,20]$. We replicated this activity pattern in the present set of experiments. Between-subject measures of activity (number of infrared beam breaks) revealed that $1 \mathrm{mg} / \mathrm{kg}$ ( -)-nicotine-di-D tartrate $(0.351 \mathrm{mg} / \mathrm{kg}$ free base $)$ initially suppressed locomotor activity relative to saline-treated rats. By the fourth nicotine administration, activity counts were above control levels.

One goal of the present study was to determine whether the initial locomotor-activating effects of novelty would be related to rats' subsequent sensitivity to the psychomotor effects of nicotine. Previous research has found that novelty-induced activity can serve as a predictive variable for a rat's sensitivity to the behavioral effects of abused drugs. This list of behaviors includes self-administration [14,15,29], drug discrimination [13], context conditioning [17], bar-press suppression [6], and locomotor activity [16,29]. Much of the research just cited reports a positive relation between reactivity to novelty and the subsequent behavioral effect of interest. In contrast, we found that nicotine disrupted individual differences that were present in saline controls. That is, HR to the first exposure to an environment (i.e., inescapable novelty) remained more active, in general, than LR even after repeated exposure to the environment. Nicotine administration (acute and chronic) disrupted this difference. Nicotine-induced activity for some LR was now in the upper half of the sampling distribution, whereas activity of some HR shifted to the lower half of the distribution. Nicotine-induced disruption of individual differences occurred regardless of whether nicotine was evoking locomotor suppression (e.g., Trial 1) or locomotor stimulation (e.g., Trial 7).

Our conclusion appears to be in direct contrast to that of previous individual differences research with nicotine (e.g., Ref. [34]). In that research, rats more activated by a novel environment (HR) were more sensitive to the locomotor-suppressant effects of nicotine, whereas LR were more sensitive to the stimulant effects of nicotine. It is important to note that these conclusions were based on measures and statistical comparisons that were susceptible to a baseline-dependency interpretation $[11,28]$. That is, HR may have shown greater sensitivity to the locomotor-suppressant effects of nicotine simply because activity in this subset of rats was initially higher. Similarly, LR likely displayed a larger relative increase in activity because their activity was initially lower. Indeed, if we assess individual differences using a within-subject shift in activity measure (i.e., nicotine-induced activity minus novelty-induced activity for the comparable time period), we observe an effect similar to past research $[34,35]$. For example, on Trial 1 (acute nicotine), HR that received only nicotine treatment displayed a significantly larger decrease in activity $(-227 \pm 17)$ than LR $(-133 \pm 17)$. Our chronic nicotine data ( e.g., Trial 7) is also consistent with past research. According to a shift measure, LR treated chronically with nicotine were significantly more sensitive to the activating effects of chronic nicotine $(62 \pm 16)$ than HR $(-23 \pm 17)$. Importantly, although the shift measures differed statistically, overall activity for HR and LR (number of infrared beam breaks) after acute and chronic administration of nicotine did not differ significantly (Trial $1: \mathrm{HR}=179 \pm 18, \mathrm{LR}=152 \pm 10$; Trial 7: $\mathrm{HR}=$ $382 \pm 21, \mathrm{LR}=347 \pm 12$ ). This latter result is consistent with the $z$-score analyses; nicotine disrupts predictable individual differences in activity that are present in a drug-free state.

We found that mecamylamine $(1 \mathrm{mg} / \mathrm{kg})$ completely prevented the acute suppressant and chronic activating effects of nicotine $[7,26,37]$. The peripheral $\mathrm{nACh}$ receptor antagonist hexamethonium, in contrast, did not block the chronic psychomotor effects of nicotine [5,7]. Interestingly, the low and high dose of mecamylamine $(0.1$ and $1 \mathrm{mg} / \mathrm{kg})$ blocked nicotine-induced locomotor suppression. Unlike the high dose, however, the low dose of mecamylamine did not prevent the chronic stimulant effects of nicotine. Whether this difference in blockade reflects differential sensitivity to mecamylamine blockade or differences in selectivity of the low and high dose of mecamylamine requires further empirical attention. Further, we found that the $10-\mathrm{mg} / \mathrm{kg}$ dose of hexamethonium partially blocked the acute locomotor-suppressant effect of nicotine. This result may indicate that nicotine-induced locomotor suppression is partially mediated by peripheral nACh receptors or that some hexamethonium at this relatively high dose was able to cross the blood/brain barrier and block central $\mathrm{nACh}$ receptors.

A second major goal of the present series of experiments was to determine if individual difference effects induced by nicotine were altered by mecamylamine or hexamethonium. Pretreatment with hexamethonium did not alter nicotine disruption of individual differences. In contrast, mecamylamine $(1 \mathrm{mg} / \mathrm{kg})$ restored individual differences. That is, rats which were classified as HR based on activity in a novel environment remained HR when treated with mecamylamine 15 min before administration of ( - -)-nicotine-di-D tartrate. Similarly, LR remained in the lower portion of the distribution given mecamylamine pretreatment. For several reasons, these results are especially interesting. First, this data pattern indicates that nicotine disrupts individual differences in activity via a centrally mediated process (i.e., neural nACh receptors). Second, and perhaps more interesting, is that these results suggest that mecamylamine does not merely make the average activity level of the group similar to saline controls. Rather, mecamylamine restores the animal's activity level back to its place in the group's distribution - as if nicotine had not been administered.

Corroborating this latter suggestion are the results of the nicotine-alone test. Recall that some rats were treated with nicotine and mecamylamine daily for seven trials. Trial 8 was a test in which mecamylamine was withheld but all rats were treated with $1 \mathrm{mg} / \mathrm{kg}(-)$-nicotine-di-D tartrate just before locomotor testing. In this nicotine-alone test, rats previously treated with the high dose of mecamylamine $(1 \mathrm{mg} /$ $\mathrm{kg}$ ) were as sensitive to the locomotor-suppressant effects of nicotine as saline controls receiving nicotine for the first time. Thus, chronic treatment of mecamylamine preceding 
nicotine did not alter sensitivity to nicotine-induced locomotor suppression. This conclusion is further supported by the clear nicotine disruption of individual differences once mecamylamine pretreatment was withheld (Fig. 3C). Finally, previous experience with hexamethonium did not affect performance in the nicotine-alone test, thus indicating the importance of central $\mathrm{nACh}$ receptors.

In sum, rats that were more active during initial exposure to an environment remained more active even after seven additional 30-min exposures to the same environment. Nicotine treatment disrupted this effect. This nicotine disruption of individual differences occurred whether nicotine suppressed or stimulated locomotor activity. Mecamylamine, but not hexamethonium restored the nicotine-induced disruption of individual differences. This result suggests that the effects of nicotine on individual differences were mediated by neural nACh receptors. Further research in understanding individual differences and the effects of nicotine will be important given the current search for pharmacotherapies for smoking cessation using nicotine and $\mathrm{nACh}$ receptor antagonists like mecamylamine ( e.g., Ref. [32]). Humans clearly show individual differences in response to nicotine (e.g., Refs. [18,22,27]). Notably, not every person exposed to nicotine via smoking tobacco becomes a chronic smoker [22]. Some people will attempt to smoke once or twice and never try again, whereas other individuals will develop an abuse pattern, smoking up to several packs of cigarettes a day. By determining predictors of individual vulnerability to drugs of abuse or to pharmacotherapies meant to prevent relapse, researchers and practitioners may be able to develop better prevention and intervention strategies [12].

\section{Acknowledgments}

Grants from the National Institute on Drug Abuse (DA11893), the Nebraska Cancer and Smoking Disease Research Program, and the University of Nebraska-Lincoln Research Council supported the research in the present report. We thank Roger Dooley for designing and constructing the automated infrared emitter/detector system used to collect the activity data. We are also grateful to David Wunderlich for numerous discussions and help with data analyses, to Todd Hinze for his technical assistance, and to Michael Bardo and Eric Fung for their thoughtful comments on an earlier version of this report.

\section{References}

[1] Antelman SM, Eichler AJ, Black CA, Kocan D. Interchangeability of stress and amphetamine in sensitization. Science 1980;207:329-31.

[2] Asghar K, Roth LJ. Entry and distribution of hexamethonium in the central nervous system. Biochem Pharmacol 1971;20:278795.

[3] Badiani A, Browman KE, Robinson TE. Influence of novel versus home enviroriments on sensitization to the psychomotor effects of cocaine and amphetamine. Brain Res 1995;674:291-8.
[4] Badiani A, Camp DM, Robinson TE. Enduring enhancement of amphetamine sensitization by drug-associated environmental stimuli. J Pharmacol Exp Ther 1997;282:787-94.

[5] Benwell MEM, Balfour DJK, Birrell CE. Desensitization of the nicotine-induced mesolinlbic dopamine responses during constant infusion with nicotine. Br J Pharmacol 1995;114:454-60.

[6] Bevins RA, Klebaur JE, BardoMT.Individual differences in response to novelty, amphetamine-induced activity and drug discrimination in rats. Behav Pharmacol 1997;8:113-23.

[7] Clarke PBS, Kumar R. The effects of nicotine on locomotor activity in nontolerant and tolerant rats. Br J Pharmacol 1983;78:329-37.

[8] Cools AR, Ellenbroek D, Lubbers L. Use of high and low responders to novelty in rat studies on the role of the ventral striatum in radial maze performance: effects of intra-accumbens injections of sulpiride. Can J Physiol Pharmacol 1993;71:335-42.

[9] Cools AR, Oingras MA. Nijmegen high and low responders to novelty: a new tool in the search after the neurobiology of drug abuse liability. Pharmacol, Biochem Behav 1998;60:151-9.

[10] Dellu F, Mayo W, Vallée M, Maccari S, Piazza PV, LeMoal $\mathrm{M}$, Simon H. Behavioral reactivity to novelty during youth as a predictive factor of stress-induced corticosterone secretion in the elderly - a life-span study in rats. Psychoneuroendocrinology 1996;21: 441-53.

[11] Dews P, Wenger O. Rate-dependency of the behavioral effects of amphetamine. In: Thompson T, Dews PB, McKim WA, editors. Advances in behavioral pharmacology, vol. I. New York: Academic Press, 1977. pp. 167-227.

[12] Donohew L, Helm D, Lawrence P, Shatzer M. Sensation seeking, marijuana use and responses to prevention messages: implications for public health campaigns. In: Watson R, editor. Prevention and treatment of drug and alcohol abuse. New Jersey: Humana Press, 1990. pp. 77-93.

[13] Exner M, Clark D. Behaviour in the novel environment predicts responsiveness to $\mathrm{D}$-amphetamine in the rat: a multivariate approach. Behav Pharmacol 1993;4:47-56.

[14] Oingras MA, Cools AR. Differential ethanol intake in high and low responders to novelty. Behav Pharmacol 1995;6:718-23.

[15] Oingras MA, Cools AR. Analysis of the biphasic locomotor response to ethanol in high and low responders to novelty: a study in Nijmegen Wistar rats. Psychopharmacology 1996;125:25864.

[16] Hooks MS, Jones OH, Liem BJ, Justice JB. Sensitization and individual differences to IP amphetamine, cocaine, or caffeine following repeated intracranial amphetamine infusions. Pharmacol, Biochem Behav 1992;43:815-23.

[17] Jodogne C, Marinelli M, LeMoal M, Piazza PV. Animals predisposed to develop amphetamine self-administration show higher susceptibility to develop contextual conditioning of both amphetamine-induced hyperlocomotion and sensitization. Brain Res 1994; 657:236-44.

[18] Jones RA. Individual differences in nicotine sensitivity. Addict Behav 1986;11:435-8.

[19] Ksir C, Hakan RL, Kellar KJ. Chronic nicotine and locomotor activity: influences of exposure dose and test dose. Psychopharmacology 1987;92:25-9. 
[20] Ksir C. Acute and chronic nicotine effects on measures of activity in rats: a multivariate analysis. Psychopharmacology 1994;115:105-9.

[21] Martin BR, Onaivi ES, Martin TJ. What is the nature of mecamylaine's antagonism of the central effects of nicotine? Biochem Pharmacol 1989;38:3391-7.

[22] McNeill AD. The development of dependence on smoking in children. Br J Addict 1991;86:589-92.

[23] Menzaghi F, Heinrichs SC, Merlo-Pich E, Tilders FJH, Koob $\mathrm{OF}$. Involvement of hypothalamic corticotropin-releasing factor neurons in behavioral responses to novelty in rats. Neurosci Lett 1994;168:139-42.

[24] Miczek KA, Mutschler NH. Activational effects of social stress on IV cocaine self-administration in rats. Psychopharmacology 1996; 128:256-64.

[25] Oitzl MS, vanHaarst AD, deKloet ER. Behavioral and neuroendocrine responses controlled by the concerted action of central mineralcorticoid (MRS) and glucocorticoid receptors (GSR). Psychoneuroendocrinology 1997;22:S87-93.

[26] Panagis G, Nisell M, Nomikos GG, Chergui K, Svensson TH. Nicotine injections into the ventral tegmental area increase locomotion and Fos-like immunoreactivity in the nucleus accumbens of the rat. Brain Res 1996;730:133-42.

[27] Perkins KA. Individual variability in responses to nicotine. Behav Genet 1995;25:119-32.

[28] Perkins KA. Baseline-dependency of nicotine effects: a review. Behav Pharmacol 1999;10:597-615.

[29] Piazza PV, Deminière J-M, LeMoal M, Simon H. Factors that predict individual vulnerability to amphetamine self-administration. Science 1989;245:1511-3.

[30] Piazza PV, Deminière J-M, LeMoal M, Simon H. Stressand pharmacologically-induced behavioral sensitization increases vulnerability to acquisition of amphetamine self-administration. Brain Res 1990;514:22-6.

[31] Piazza PV, LeMoal M. Pathophysiological basis of vulnerability to drug abuse: role of and interaction between stress, glucocorticoids, and dopaminergic neurons. Annu Rev Pharmacol Toxicol 1996; 36:359-78.

[32] Rose JE, Behm FM, Westman EC. Nicotine-mecamylamine treatment for smoking cessation: the role of pre-cession therapy. Exp Clin Psychopharmacol 1998;6:331-43.

[33] Rosecrans JA. Forebrain biogenic amine function in high and low active female rats. Physiol Behav 1970;5:453-8.

[34] Rosecrans JA. Effects of nicotine on behavioral arousal and brain 5-hydroxytryptamine function in female rats selected for differences in activity. Eur J Pharmacol 1971;14:29-37.

[35] Rosecrans JA. The psychopharmacological basis of nicotine's differential effects on behavior: individual subject variability in the rat. Behav Genet 1995;25:187-96.

[36] Stolerman IP, Fink R, Jarvik ME. Acute and chronic tolerance to nicotine measured by activity in rats. Psychopharmacologia 1973;30:329-42.

[37] Stolerman IP, Garcha HS, Mirza NR. Dissociation between the locomotor stimulant and depressant effects of nicotinic agonists in rats. Psychopharmacology 1995;117:430-7. 